\title{
Relationship between Cough-Associated Changes in CSF Flow and Disease Severity in Chiari I Malformation: An Exploratory Study Using Real-Time MRI
}

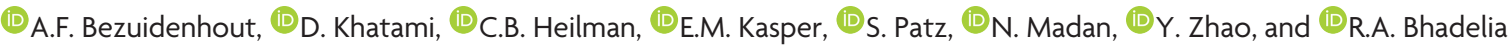

\begin{abstract}
BACKGROUND AND PURPOSE: Currently no quantitative objective test exists to determine disease severity in a patient with Chiari I malformation. Our aim was to correlate disease severity in symptomatic patients with Chiari I malformation with cough-associated changes in CSF flow as measured with real-time MR imaging.
\end{abstract}

MATERIALS AND METHODS: Thirteen symptomatic patients with Chiari I malformation (tonsillar herniation of $\geq 5 \mathrm{~mm}$ ) were prospectively studied. A real-time, flow-sensitized pencil-beam MR imaging scan was used to measure CSF stroke volume during rest and immediately following coughing and relaxation periods (total scan time, 90 seconds). Multiple posterior fossa and craniocervical anatomic measurements were also obtained. Patients were classified into 2 groups by neurosurgeons blinded to MR imaging measurements: 1) nonspecific Chiari I malformation (5/13)—Chiari I malformation with nonspecific symptoms like non-cough-related or mild occasional cough-related headache, neck pain, dizziness, paresthesias, and/or trouble swallowing; 2) specific Chiari I malformation (8/13) — patients with Chiari I malformation with specific symptoms and/or objective findings like severe cough-related headache, myelopathy, syringomyelia, and muscle atrophy. The Spearman correlation was used to determine correlations between MR imaging measurements and disease severity, and both groups were also compared using a Mann-Whitney $U$ test.

RESULTS: There was a significant negative correlation between the percentage change in CSF stroke volume (resting to postcoughing) and Chiari I malformation disease severity $(R=0.59 ; P=.03)$. Mann-Whitney comparisons showed the percentage change in CSF stroke volume (resting to postcoughing) to be significantly different between patient groups $(P=.04)$. No other CSF flow measurement or anatomic measure was significantly different between the groups.

CONCLUSIONS: Our exploratory study suggests that assessment of CSF flow response to a coughing challenge has the potential to become a valuable objective noninvasive test for clinical assessment of disease severity in patients with Chiari I malformation.

ABBREVIATIONS: $\mathrm{CMI}=$ Chiari I malformation; $\mathrm{NS}-\mathrm{CMI}=$ Chiari I malformation with nonspecific symptoms; $\mathrm{PBI}=$ pencil-beam imaging; $\mathrm{S}$-CMI = Chiari I malformation with specific symptoms; $\mathrm{SV}_{\mathrm{CSF}}=\mathrm{CSF}$ stroke volume

$\mathrm{H}$

ans Chiari first described the spectrum of Chiari malformations during the end of the 19th century, and in 1985, Aboulezz et $\mathrm{al}^{1}$ described the radiologic definition of Chiari I malformation (CMI) as a $\geq 5$ - $\mathrm{mm}$ downward displacement of the cerebellar tonsils through the foramen magnum. Much controversy has arisen regarding the management of these patients since

Received February 17, 2018; accepted after revision March 21.

From the Departments of Radiology (A.F.B., D.K., R.A.B.) and Neurosurgery (E.M.K.), Beth Israel Deaconess Medical Center, Boston, Massachusetts; Departments of Neurosurgery (C.B.H.) and Radiology (N.M.), Tufts Medical Center, Boston, Massachusetts; Department of Radiology (S.P.), Brigham and Woman's Hospital, Boston, Massachusetts; and Philips Healthcare (Y.Z.), Boston, Massachusetts.

This work was supported by a grant from the Conquer Chiari Foundation.

Please address correspondence to Fourie Bezuidenhout, MD, Department of Radiology, Beth Israel Deaconess Medical Center, WCB90, 330 Brookline Ave, Boston, MA 02215; e-mail: abezuide@bidmc.harvard.edu; @Fouriebez

http://dx.doi.org/10.3174/ajnr.A5670 then because $\mathrm{CMI}$ is not an infrequent $\mathrm{MR}$ imaging finding in the general population with a prevalence of $0.56 \%-0.77 \%{ }^{2,3}$ The conundrum exists because some patients who meet the MR imaging criteria for CMI are asymptomatic and some with $<5$-mm tonsillar herniation have typical CMI symptoms. ${ }^{4-10}$ It has been estimated that at present, only $20 \%$ of patients diagnosed as having CMI by current MR imaging criteria will have symptoms amenable to surgical intervention. ${ }^{11}$ Because there is no reliable objective test available that correlates with the severity of clinical findings, the treatment of these patients largely depends on the management philosophy of the treating neurosurgeon. Reportedly, this has led to the overzealous use of surgical treatment with unfavorable outcomes being reported in up to $30 \%$ of patients. ${ }^{6,12}$

Most of the symptoms and clinical findings associated with CMI are believed to be due either to neural compression or abnormal CSF circulation at the foramen magnum. ${ }^{5,7,13-23}$ Because 


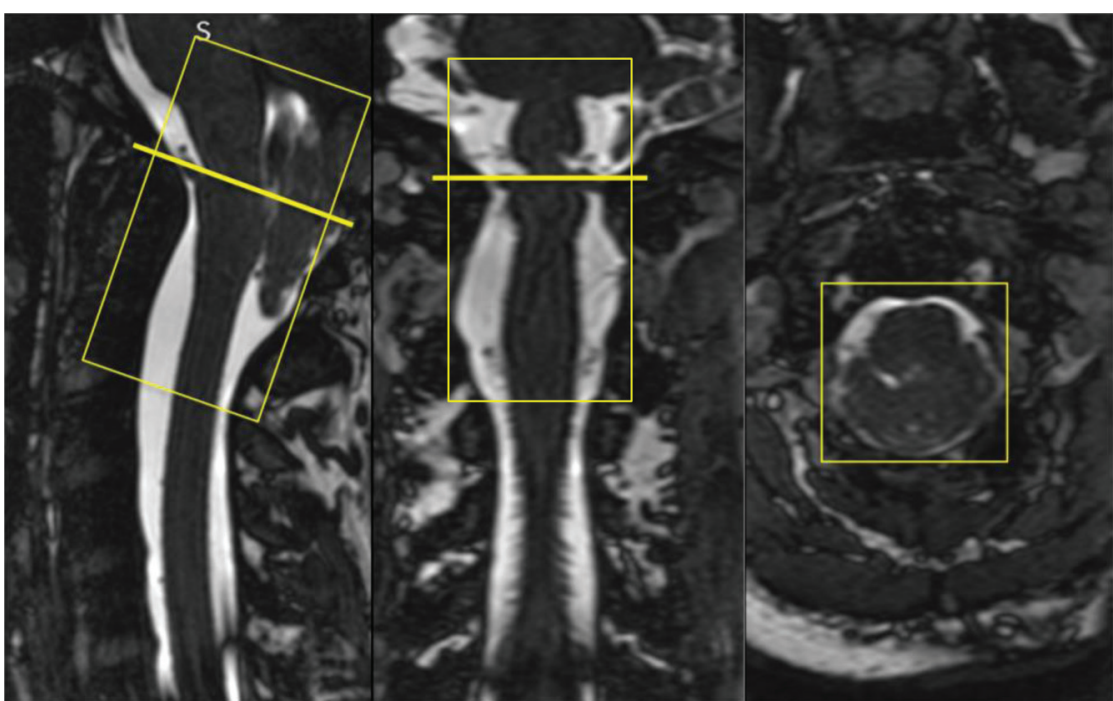

FIG 1. The position of the PBI cylinder (rectangle) and location of CSF flow evaluation (line) are shown in a patient with CMI.

both of these pathologic forces are likely to be interrelated within the bony confines of the foramen magnum, assessment of fluid dynamics by CSF pressure or flow measurements at the craniocervical junction may better reflect CMI disease severity than MR imaging-based anatomic measurements like tonsillar herniation or posterior fossa volume. ${ }^{21,23-26}$ Thus, both invasive simultaneous pressure measurements in the head and spinal canal and noninvasive CSF flow imaging using cine phase-contrast MR imaging have been used. ${ }^{5,7,13-16,27-31}$ However, none of the above methods have been widely accepted for presurgical evaluation of individual patients with CMI: pressure measurements due to their invasive nature and cine phase-contrast due to wide variability in quantitative CSF flow estimates between patients with CMI of different disease severities (as well as between healthy subjects and patients with CMI).

An important limitation of previous cine phase-contrast methods is that most assess CSF flow while the patient is breathing quietly in the MR imaging scanner and provide weighted averages of CSF flow pulsations over $\geq 15$ cardiac cycles. Because physiologic challenges such as coughing or the Valsalva maneuver are known to transiently induce or exaggerate pressure dissociations at the craniocervical junction affecting CSF flow for only a few seconds, these weighted averages of CSF flow over many cardiac cycles measured by cine phase-contrast may not capture transient changes in CSF flow. ${ }^{21-23,32-35}$ In a recent study, Bhadelia et al ${ }^{32}$ proposed a real-time CSF flow imaging technique to assess the transient changes in CSF flow as a consequence of physiologic maneuvers. This technique was further used to compare CSF flow response to coughing in patients with CMI and healthy subjects. ${ }^{33}$ In this exploratory study, we used real-time MR imaging to correlate disease severity among symptomatic patients with CMI with cough-associated changes in CSF flow.

\section{MATERIALS AND METHODS}

Institutional review board approval was obtained for this Health Insurance Portability and Accountability Act-compliant prospective study, and each patient signed an informed consent.

\section{Patients}

Thirteen symptomatic patients with CMI who agreed to participate in a research study at the initial neurosurgical consultation were prospectively evaluated between 2011 and 2013. Two board-certified neurosurgeons with $>15$ years of experience in Chiari care developed a grading scale for symptom severity by consensus (slightly modified from a previously published CMI study, Alperin et al 2014 ${ }^{36}$ ). Subsequently, this grading system was used by the neurosurgeons blinded to MR imaging measurements to classify patients in to 2 groups: 1) nonspecific CMI (NS$\mathrm{CMI}$ ): CMI with nonspecific symptoms like non-cough-related or mild occasional cough-related headache, neck pain, dizziness, paresthesias, and/or dysphagia; 2) specific-CMI (S-CMI): patients with CMI with specific symptoms and/or objective findings like severe cough-related headache, myelopathy, syringomyelia, and muscle atrophy.

\section{MR Imaging}

All patients underwent MR imaging on a 3T scanner (Achieva; Philips Healthcare, Best, the Netherlands).

For localization and anatomic measurements of the posterior fossa and craniocervical junction, sagittal 3D T1 and 3D T2-weighted images were obtained. To assess CSF flow, we used a real-time flowsensitized pencil-beam imaging (PBI) method with $\sim 50$-ms temporal resolution. PBI excites a narrow cylinder or "pencil" region and has been described in detail previously. ${ }^{32,37,38}$ A 25-mm-diameter and 64-mm-length cylinder with bipolar velocity-encoding and readout gradients applied along the long axis of the cylinder (pencil beam) was positioned along the long axis of the upper cervical spinal canal, extending from just above the level of the foramen magnum to the C3 level covering the entire thecal sac' (Fig 1). ${ }^{32,33}$ The PBI scan provides a phase-encoded velocity measurement with a temporal resolution of $\sim 50 \mathrm{~ms}$ and spatial resolution along the cylinder axis. ${ }^{38}$ To avoid phase wrap, we used a velocity encoding of $5 \mathrm{~cm} / \mathrm{s}$ along the superior-to-inferior direction. Other imaging parameters were TR, 25-28 ms; TE, $3.8 \mathrm{~ms}$; and flip angle, $5^{\circ}$. The bipolar phase-encoding gradient was alternated on sequential TRs, making the effective temporal resolution $2 \times$ TR (ie, 50-56 ms). Heart rate and respiratory movements were continuously monitored using the physiologic recording system of the scanner. Cardiac gating was not required for this PBI study, which recorded pulsatile CSF flow motion in realtime and, therefore, was able to acquire data much faster than the gated phase-contrast MR imaging.

Each PBI scan was acquired for approximately 90 seconds, during which the patient was asked to do the following: 1) breathe quietly for the first 15-20 seconds (by counting from 1 to 20), 2) then cough as forcefully as possible consecutively 6 times, and 3) breathe quietly again after the end of coughing. Each 90-second scan set was repeated 3 times. 


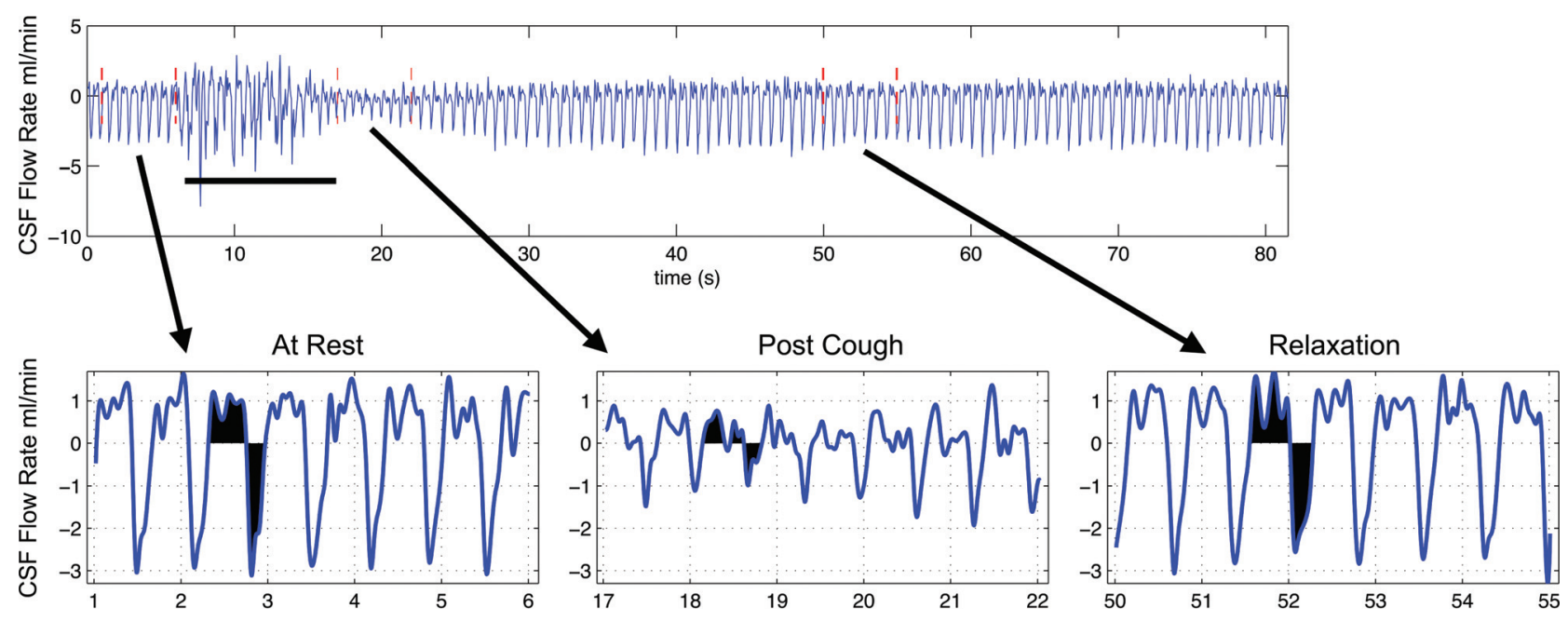

FIG 2. The effect of coughing on a cardiac cycle-related CSF flow waveforms is seen in a patient with CMI with specific symptoms. Left-to-right: resting, coughing (underlined), postcoughing, and relaxation waveforms are seen. CSF flow waveforms: craniocaudal CSF flow (area colored in below the zero line) and caudocranial CSF flow (area colored in above the zero line). CSF stroke volume is the average of absolute flow from craniocaudal and caudocranial CSF flow. In this patient with CMI with specific symptoms, the CSF flow-pulsation magnitude in the immediate postcoughing period decreases in comparison with the resting value before gradually returning to the resting level at relaxation. The $x$-axis indicates time in seconds; the y-axis, CSF flow rate in milliliters per minute. Arrows indicate a magnified view of the CSF flow waveforms during the respective actions performed by the patient.

\section{Image Analysis}

$3 \mathrm{D}$ anatomic images were used to measure the amount of tonsillar herniation below the level of the foramen magnum as well as multiple posterior fossa and craniocervical dimensions and angles. Posterior fossa measurements included the length of the clivus (inferior boundary of the dorsum sellae to the basion), supraocciput (opisthion to the internal occipital protuberance), the McRae line (basion to the opisthion), and the Twining line (inferior boundary of the dorsum sellae to the internal occipital protuberance). Craniocervical measurements included the clivus-canal angle (clival-axis angle), odontoid retroversion angle (posterior inclination of the odontoid relative to the body of C2), skull base angle (from the nasion to the center of the pituitary fossa to the clivus/basion), and the $\mathrm{pB}-\mathrm{C} 2$ line (perpendicular length between a line connecting the basion and the inferoposterior C2 body to the ventral dura).

The posterior fossa and craniocervical measurements were manually obtained using the midsagittal image on a PACS workstation.

CSF flow analysis was performed off-line using custom software developed in Matlab (MathWorks, Natick, Massachusetts), which allows simultaneous display of $3 \mathrm{D}$ anatomic and physiologic PBI data along with the heart rate and respiration. The crosssectional area of the CSF flow channel of a patient within the PBI cylinder was determined on axial anatomic images by subtracting the area of the neural structures from the area of the thecal sac at that level. ${ }^{39}$ The software then calculated CSF flow in milliliters per second by multiplying average PBI velocity by the area of CSF flow channel. CSF flow waveforms were plotted with CSF flow on the $\mathrm{y}$-axis versus time (seconds) on the $\mathrm{x}$-axis, thereby depicting cardiac cycle-related CSF flow pulsations over the entire 90-second data acquisition, encompassing resting, postcoughing, and relaxation (delayed) periods. The physiologic parameter measured was CSF stroke volume $\left(\mathrm{SV}_{\mathrm{CSF}}\right)$ in milliliters, which was defined as the average of the absolute values of integrated cranio- caudal and caudocranial CSF flows during the entire cardiac cycle (Fig 2). ${ }^{40}$

The $\mathrm{SV}_{\mathrm{CSF}}$ for each period was calculated during a 5- to 6-second period. For postcoughing assessment, the period was selected approximately 5 seconds after the end of coughing to allow sufficient time for any motion related to coughing to subside. The relaxation assessment was performed about 20-25 seconds after coughing. We assessed CSF flow just below the level of foramen magnum along the PBI cylinder. No discontinuities were present on the phase images to indicate aliasing (no velocities exceeding $5 \mathrm{~cm} / \mathrm{s})$.

All anatomic and CSF flow measurements for this exploratory study were obtained by consensus by 2 radiologists with 25 and 3 years of clinical experience but without the knowledge of the clinical severity grade of the patients.

\section{Data Analysis}

Besides using resting, postcoughing, and relaxation values of $\mathrm{SV}_{\mathrm{CSF}}$ as physiologic measurements, change in the $\mathrm{SV}_{\mathrm{CSF}}$ between resting to postcoughing, postcoughing to relaxation, and resting to relaxation was also evaluated and expressed in a percentage of initial values for normalization of differences among patients. The Spearman correlation was used to determine relationships between anatomic and physiologic CSF flow measurements and CMI disease severity. A Mann-Whitney $U$ test was used to compare anatomic and physiologic measurements between NS-CMI and S-CMI patient groups. A $P$ value of $<.05$ was statistically significant.

\section{RESULTS}

Thirteen symptomatic patients with CMI were included. They were a mean of $38.6 \pm 6.7$ years of age, and 11/12 (92\%) were women. The patients were divided into 2 groups based on symptoms by neurosurgeons as described in the "Materials and Methods" section. Group 1 included patients with nonspecific CMI 
S-CMI $(n=8)$

\begin{tabular}{lcc}
\hline Anatomic measurements (mean) & & \\
Tonsillar herniation (mm) & $17.5 \pm 7.4$ & $12.2 \pm 6.2$ \\
Clivus length (mm) & $34.3 \pm 5.4$ & $32.8 \pm 2.5$ \\
Supraocciput length (mm) & $42.4 \pm 7.7$ & $40.4 \pm 2.5$ \\
Twining line (mm) & $81.4 \pm 4.8$ & $81.8 \pm 1.3$ \\
McRae line (mm) & $36.6 \pm 4.2$ & $39 \pm 3.4$ \\
Skull base angle & $131.1^{\circ} \pm 6.9^{\circ}$ & $125.6^{\circ} \pm 4.8^{\circ}$ \\
Odontoid retroversion angle & $69.8^{\circ} \pm 9.3^{\circ}$ & $70.4^{\circ} \pm 8.7^{\circ}$ \\
Clivus-canal angle & $145.5^{\circ} \pm 10.4^{\circ}$ & $150.6^{\circ} \pm 6.9^{\circ}$ \\
PB-C2 Line (mm) & $6.1 \pm 2$ & $7.2 \pm 1.5$ \\
Physiologic measurements (mean) & & \\
SV $_{\text {CSF }}$ resting (mL) & $0.37 \pm 0.27$ & $0.48 \pm 0.20$ \\
SV $_{\text {CSF postcough (mL) }}$ & $0.14 \pm 0.13$ & $0.29 \pm 0.13$ \\
SV $_{\text {CSF }}$ relaxation (mL) & $0.36 \pm 0.31$ & $0.51 \pm 0.20$ \\
$\Delta$ SV $_{\text {CSF }}$ resting to postcough (\%) & $-64.9 \pm 17.3^{\mathrm{a}}$ & $-35.1 \pm 29.6^{\mathrm{a}}$ \\
$\Delta \mathrm{SV}_{\text {CSF }}$ postcough to relaxation (\%) & $190 \pm 158$ & $98.1 \pm 115.7$ \\
$\Delta \mathrm{SV}_{\mathrm{CSF}}$ resting to relaxation (\%) & $-9.6 \pm 37.6$ & $9.3 \pm 27.3$ \\
\hline
\end{tabular}

Note:- $\Delta S V_{C S F}$ resting to postcough indicates change in $\mathrm{SV}_{\mathrm{CSF}}$ from resting to postcough in $\% ; \Delta S \mathrm{~V}_{\mathrm{CSF}}$ postcough to relaxation, change in $\mathrm{SV}_{\mathrm{CSF}}$ from postcough to relaxation in \%; $\Delta \mathrm{SV}_{\mathrm{CSF}}$ resting to relaxation, change in $\mathrm{SV}_{\mathrm{CSF}}$ from resting to relaxation in \%.

a $P<.05$, Mann-Whitney $U$ test.

symptoms and consisted of 5 (5/13) patients. Group 2 included patients with specific CMI symptoms and consisted of $8(8 / 13)$ patients.

No statistically significant relationship was observed between anatomic measurements and CMI disease severity. There was a statistically significant negative relationship observed between the percentage change in $\mathrm{SV}_{\mathrm{CSF}}$ from resting to postcoughing and CMI disease severity $(R=0.59 ; P=.03)$.

Anatomic and physiologic CSF flow measurements of NSCMI and S-CMI groups are shown in the Table. The Mann-Whitney $U$ test showed the percentage change in the $\mathrm{SV}_{\mathrm{CSF}}$ from resting to postcough to be the only MR imaging measurement significantly different between the groups $(P=.04)$. The change in the $\mathrm{SV}_{\mathrm{CSF}}$ is graphically demonstrated in a patient with S-CMI with cough and Valsalva-related headache and syringomyelia (Fig 2).

Figure 3 shows the effect of coughing in a patient with NS-CMI compared with S-CMI. No appreciable change in CSF flow is seen in a patient with NS-CMI after coughing, but in the patient with S-CMI, considerable decrease is clearly visualized.

\section{DISCUSSION}

In this exploratory study, real-time physiologic measurement of CSF flow demonstrated a significant decrease in flow across the foramen magnum in response to coughing in patients with CMI with severe specific symptoms compared with those with CMI with nonspecific symptoms. Real-time physiologic measurement of decreased CSF flow after coughing demonstrated better correlation with CMI disease severity than any of the anatomic measurements of the posterior fossa or craniocervical junction. Another important finding of the study was that no significant difference in the $\mathrm{SV}_{\mathrm{CSF}}$ was seen between the 2 groups of patients with CMI in resting or relaxation periods and only a borderline significant difference $(P=.07)$ was seen in the postcoughing values. The observation that only the percentage change in CSF flow from resting to postcoughing showed a significant difference between the 2 groups underscores the importance of the use of nor- malized values of CSF flow in objective quantitative physiology-based assessment of CSF flow obstruction at the foramen magnum in an individual patient with CMI. In other words, each patient acted as his or her own control by using a physiologic challenge to assess his or her ability to handle compensatory flow across the foramen magnum and thereby negating confounding variables among patients. The results of this exploratory study are encouraging enough to pursue a larger prospective study of patients with CMI to determine whether this method can be used as an objective clinical test for assessing disease severity.

Previously published invasive pressure studies have shown that physiologic challenges such as coughing or Valsalva maneuver produce pressure dissociation between the head and spine in patients with CMI. ${ }^{21,23,24,32-35}$ The development of pressure dissociation is explained by a transient increase in spinal pressure (from increased intrathoracic pressure and consequent distension of the epidural veins) during coughing, moving CSF to the head, which returns to the spinal canal immediately postcoughing in a healthy subject but not in a patient with CMI, provided there is sufficient foramen magnum obstruction due to neural crowding. ${ }^{22,33-35}$ These studies also demonstrated that there was minimal if any pressure dissociation in these patients with CMI at rest before coughing or Valsalva. ${ }^{33}$ While we did not calculate pressure gradients from our velocity data, our results confirmed both of these observations made by previous invasive pressure studies. ${ }^{34,35,41}$ First, a decrease in CSF flow after coughing in patients with CMI indicates that CSF circulation from the head to spine is impaired, a condition that would result in pressure dissociation. Second, a decrease in CSF flow after coughing was transient, lasting only a few seconds before returning to the resting levels in the relaxation period. This finding suggests that there is increased pressure dissociation in the postcoughing period due to further downward descent of cerebellar tonsils exaggerating neural crowding at the foramen magnum. ${ }^{23}$ This exaggeration of neural crowding and further obstruction of CSF flow are believed to result in exacerbation of symptoms after coughing..$^{23,32-35}$ Our observation thus strongly suggests that MR imaging assessment of CSF flow in CMI would be much more informative in assessing the CSF circulation abnormalities if performed with a physiologic challenge.

Our results provide the first evidence of differences in CSF flow in response to coughing in 2 groups of symptomatic patients with CMI, which were classified on the basis of symptoms and clinical findings. While this is a small exploratory study, it suggests that there is a higher degree of transient CSF flow impairment after coughing in patients with CMI with specific symptoms and objective findings - that is, more severe disease than in those with nonspecific symptoms. Furthermore, unlike invasive pressure monitoring, the method described here is noninvasive and has the potential to be used in studying many patients with CMI 

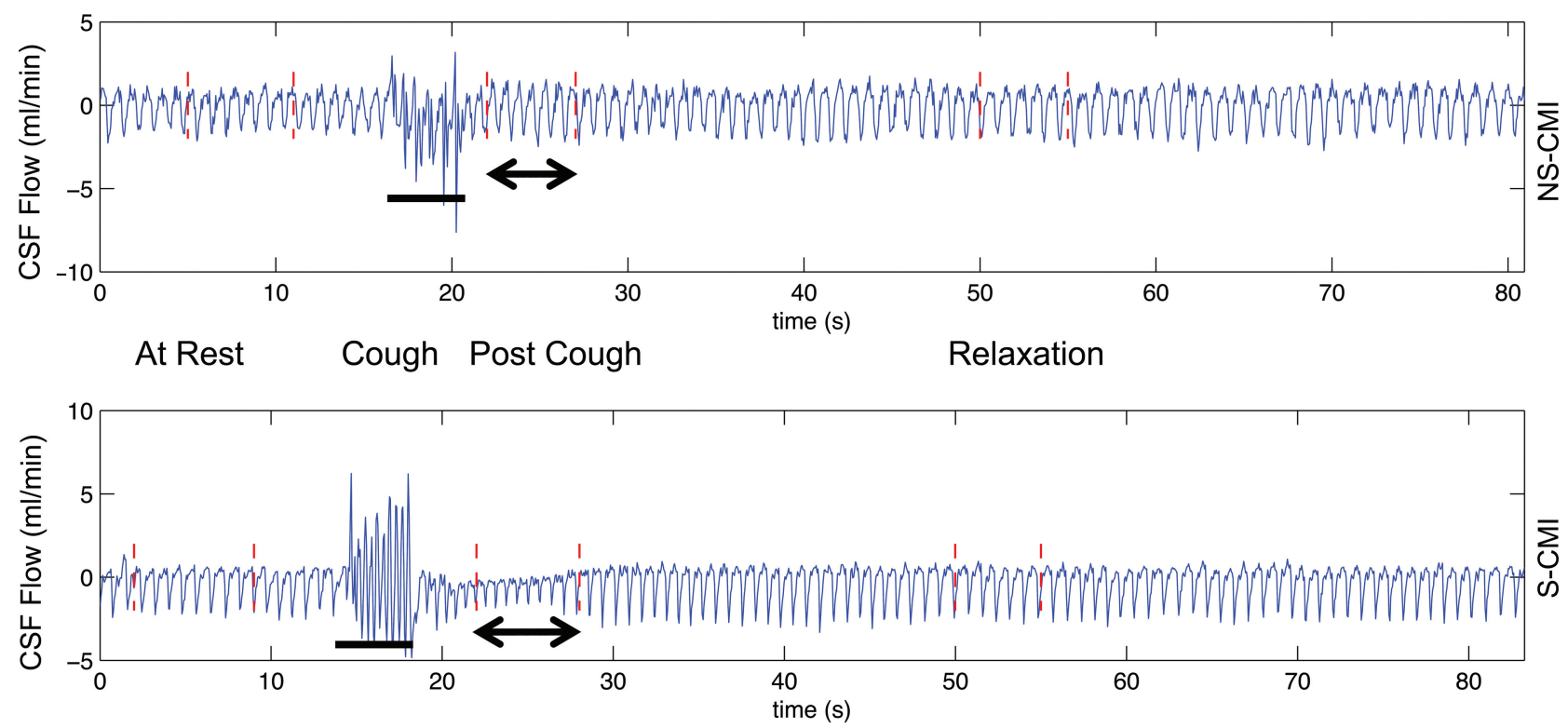

FIG 3. The effect of coughing on cardiac cycle-related CSF flow waveforms in different patients with CMI, one with nonspecific symptoms and one with specific symptoms. Left-to-right: resting, coughing (underlined), postcoughing (underlined with double-headed arrows), and relaxation waveforms are seen. In the patient with S-CMI (lower waveform), the CSF flow-pulsation magnitude in the immediate postcoughing period decreases to $\pm 50 \%$ of the resting value before gradually returning to the resting level at relaxation. In contrast, in the patient with NS-CMI, the CSF flow-pulsation magnitude immediately postcoughing is not significantly different compared with that of the resting period. The $x$-axis indicates time in seconds; the $y$-axis, CSF flow rate, in milliliters per minute.

with different grades of disease severity and to follow-up patients treated with or without surgical decompression.

Several limitations of our exploratory study (and method) need to be addressed. First, the small sample size limits our ability to recommend it as an objective test for patients with CMI until further patient data are collected in a larger prospective study. However, even in this small group of patients, cough-associated changes in CSF flow were the only anatomic or physiologic parameter that demonstrated a statistically significant difference between patients with NS-CMI and S-CMI, highlighting their potential in objectively assessing disease severity in patients with CMI. Second, due to small sample size, we could only divide patients with CMI into 2 groups as has been done by many previous CMI studies. Given the wide variety of symptoms and clinical findings in CMI, we believe that dividing CMI disease severity into only 2 groups is a limitation that needs to be addressed in the future, including separate assessment of patients with CMI with syringomyelia to further elucidate its pathophysiology. Third, we did not quantitatively measure coughing effort by patients but asked them to cough as forcefully as possible, which could potentially introduce an additional variable that was not accounted for in our study. We have since developed a method to quantitatively assess cough effort during our MR imaging experiments to better evaluate CSF flow changes in individual patients. However, we believe cough effort to be less of an issue in the group comparison performed here. This is because patients with severe symptoms (S-CMI) are more likely to not cough forcefully due to fear of inducing pain than those with less severe symptoms (NS-CMI) and thus may have introduced a negative bias, if any, thus further enhancing our results. Fourth, due to the small sample size in this exploratory study, interobserver variability between the neurosurgeons classifying the patients and radiologists reading the MR imaging studies, respectively, was not ana- lyzed, but in both situations, decisions were made by consensus. Finally, the pencil-beam sequence used here is currently only available in research mode on 1 vendor platform. If this method is to be used in routine clinical practice for CSF flow studies in patients with CMI, expanding it across different vendor platforms is required.

\section{CONCLUSIONS}

Our exploratory study suggests a potential future role for realtime physiologic measurement of CSF flow in response to coughing as an objective qualifier for clinical assessment in patients with CMI.

Disclosures: Ekkehard M. Kasper—UNRELATED: Board Membership: Editorial Boards of Neurosurgery, Neurooncology, others; Consultancy: Risk Management Foundation of The Harvard Medical Institutions, Comments: legal expert review as an external specialist; Expert Testimony: CRICO; Travel/Accommodations/Meeting Expenses Unrelated to Activities Listed: World Federation of Neurosurgical Societies Committee on Anatomy, Comments: For educational courses to which we are invited as a World Federation of Neurosurgical Societies committee, the venue will provide room and board. We pay for our own airfare. Yansong Zhao-UNRELATED: Employment: Philips Healthcare. Rafeeque A. Bhadelia—RELATED: Grant: Conquer Chiari Foundation, Comments: money for MRI scans and analysis software. * $M o n e y$ paid to the institution.

\section{REFERENCES}

1. Aboulezz AO, Sartor K, Geyer CA, et al. Position of cerebellar tonsils in the normal population and in patients with Chiari malformation: a quantitative approach to MR imaging. J Comput Assist Tomogr 1985;9:1033-36 CrossRef Medline

2. Elster $\mathrm{AD}$, Chen MY. Chiari I malformations: clinical and radiologic reappraisal. Radiology 1992;183:347-53 CrossRef Medline

3. Meadows J, Kraut M, Guarnieri M, et al. Asymptomatic Chiari Type I malformations identified on magnetic resonance imaging. J Neurosurg 2000;92:920-26 Medline

4. Alden TD, Ojemann JG, Park TS. Surgical treatment of Chiari I 
malformation: indications and approaches. Neurosurg Focus 2001; 11:E2 Medline

5. Alperin N, Sivaramakrishnan A, Lichtor T. Magnetic resonance imaging-based measurements of cerebrospinal fluid and blood flow as indicators of intracranial compliance in patients with Chiari malformation. J Neurosurg 2005;103:46-52 CrossRef Medline

6. Baisden J. Controversies in Chiari I malformations. Surg Neurol Int 2012;3(Suppl 3):S232-37 CrossRef Medline

7. Hofkes SK, Iskandar BJ, Turski PA, et al. Differentiation between symptomatic Chiari I malformation and asymptomatic tonsillar ectopia by using cerebrospinal fluid flow imaging: initial estimate of imaging accuracy. Radiology 2007;245:532-40 CrossRef Medline

8. Sekula RF Jr, Arnone GD, Crocker C, et al. The pathogenesis of Chiari I malformation and syringomyelia. Neurol Res 2011;33: 232-39 CrossRef Medline

9. Shaffer N, Martin BA, Rocque B, et al. Cerebrospinal fluid flow impedance is elevated in Type I Chiari malformation. J Biomech Eng 2014;136:021012 CrossRef Medline

10. Voelker R. Chiari conundrum: researchers tackle a brain puzzle for the 21st century. JAMA 2009;301:147-49 CrossRef Medline

11. Tubbs RS, Beckman J, Naftel RP, et al. Institutional experience with $\mathbf{5 0 0}$ cases of surgically treated pediatric Chiari malformation type I. J Neurosurg Pediatr 2011;7:248-56 CrossRef Medline

12. Aliaga L, Hekman KE, Yassari R, et al. A novel scoring system for assessing Chiari malformation type I treatment outcomes. Neurosurgery 2012;70:656-64; discussion 664-65 CrossRef Medline

13. Alperin N, Kulkarni K, Loth F, et al. Analysis of magnetic resonance imaging-based blood and cerebrospinal fluid flow measurements in patients with Chiari I malformation: a system approach. Neurosurg Focus 2001;11:E6 Medline

14. Armonda RA, Citrin CM, Foley KT, et al. Quantitative cine-mode magnetic resonance imaging of Chiari I malformations: an analysis of cerebrospinal fluid dynamics. Neurosurgery 1994;35:214-23; discussion 223-24 CrossRef Medline

15. Bhadelia RA, Bogdan AR, Wolpert SM, et al. Cerebrospinal fluid flow waveforms: analysis in patients with Chiari I malformation by means of gated phase-contrast MR imaging velocity measurements. Radiology 1995;196:195-202 CrossRef Medline

16. Haughton VM, Korosec FR, Medow JE, et al. Peak systolic and diastolic CSF velocity in the foramen magnum in adult patients with Chiari I malformations and in normal control participants. AJNR Am J Neuroradiol 2003;24:169-76 Medline

17. Hofmann E, Warmuth-Metz M, Bendszus M, et al. Phase-contrast MR imaging of the cervical CSF and spinal cord: volumetric motion analysis in patients with Chiari I malformation. AJNR Am J Neuroradiol 2000;21:151-58 Medline

18. McGirt MJ, Nimjee SM, Floyd J, et al. Correlation of cerebrospinal fluid flow dynamics and headache in Chiari I malformation. Neurosurgery 2005;56:716-21; discussion 716-21 CrossRef Medline

19. Oldfield EH, Muraszko K, Shawker TH, et al. Pathophysiology of syringomyelia associated with Chiari I malformation of the cerebellar tonsils. Implications for diagnosis and treatment. J Neurosurg 1994;80:3-15 CrossRef Medline

20. Quigley MF, Iskandar B, Quigley ME, et al. Cerebrospinal fluid flow in foramen magnum: temporal and spatial patterns at MR imaging in volunteers and in patients with Chiari I malformation. Radiology 2004;232:229-36 CrossRef Medline

21. Sansur CA, Heiss JD, DeVroom HL, et al. Pathophysiology of headache associated with cough in patients with Chiari I malformation. J Neurosurg 2003;98:453-58 CrossRef Medline

22. Williams B. Cerebrospinal fluid pressure changes in response to coughing. Brain 1976;99:331-46 CrossRef Medline
23. Williams B. Cough headache due to craniospinal pressure dissociation. Arch Neurol 1980;37:226-30 CrossRef Medline

24. Heiss JD, Patronas N, DeVroom HL, et al. Elucidating the pathophysiology of syringomyelia. J Neurosurg 1999;91:553-62 CrossRef Medline

25. Tachibana S, Iida H, Yada K. Significance of positive Queckenstedt test in patients with syringomyelia associated with Arnold-Chiari malformations. J Neurosurg 1992;76:67-71 CrossRef Medline

26. Williams B. On the pathogenesis of syringomyelia: a review. $J R$ Soc Med 1980;73:798-806 CrossRef Medline

27. Iskandar BJ, Quigley M, Haughton VM. Foramen magnum cerebrospinal fluid flow characteristics in children with Chiari I malformation before and after craniocervical decompression. J Neurosurg 2004;101(2 Suppl):169-78 Medline

28. Levy LM, Di Chiro G. MR phase imaging and cerebrospinal fluid flow in the head and spine. Neuroradiology 1990;32:399-406 CrossRef Medline

29. McGirt MJ, Atiba A, Attenello FJ, et al. Correlation of hindbrain CSF flow and outcome after surgical decompression for Chiari I malformation. Childs Nerv Syst 2008;24:833-40 CrossRef Medline

30. McGirt MJ, Nimjee SM, Fuchs HE, et al. Relationship of cine phasecontrast magnetic resonance imaging with outcome after decompression for Chiari I malformations. Neurosurgery 2006;59:140 - 46; discussion 140-46 CrossRef Medline

31. Sakas DE, Korfias SI, Wayte SC, et al. Chiari malformation: CSF flow dynamics in the craniocervical junction and syrinx. Acta Neurochir (Wien) 2005;147:1223-33 CrossRef Medline

32. Bhadelia RA, Madan N, Zhao Y, et al. Physiology-based MR imaging assessment of CSF flow at the foramen magnum with a Valsalva maneuver. AJNR Am J Neuroradiol 2013;34:1857-62 CrossRef Medline

33. Bhadelia RA, Patz S, Heilman C, et al. Cough-associated changes in CSF flow in Chiari I malformation evaluated by real-time MRI. AJNR Am J Neuroradiol 2016;37:825-30 CrossRef Medline

34. Williams B. Simultaneous cerebral and spinal fluid pressure recordings, I: technique, physiology, and normal results. Acta Neurochir (Wien) 1981;58:167-85 CrossRef Medline

35. Williams B. Simultaneous cerebral and spinal fluid pressure recordings, 2: cerebrospinal dissociation with lesions at the foramen magnum. Acta Neurochir (Wien) 1981;59:123-42 CrossRef Medline

36. Alperin N, Loftus JR, Oliu CJ, et al. MRI measures of posterior cranial fossa morphology and CSF physiology in Chiari malformation type I. Neurosurgery 2014;75:515-22; discussion 522 CrossRef Medline

37. Hardy CJ, Pearlman JD, Moore JR, et al. Rapid NMR cardiography with a half-echo M-mode method. J Comput Assist Tomogr 1991;15: 868-74 CrossRef Medline

38. Maier SE, Hardy CJ, Jolesz FA. Brain and cerebrospinal fluid motion: real-time quantification with M-mode MR imaging. Radiology 1994;193:477-83 Medline

39. Bhadelia RA, Bogdan AR, Kaplan RF, et al. Cerebrospinal fluid pulsation amplitude and its quantitative relationship to cerebral blood flow pulsations: a phase-contrast MR flow imaging study. Neuroradiology 1997;39:258-64 CrossRef Medline

40. Bradley WG Jr, Scalzo D, Queralt J, et al. Normal-pressure hydrocephalus: evaluation with cerebrospinal fluid flow measurements at MR imaging. Radiology 1996;198:523-29 CrossRef Medline

41. Alperin NJ, Lee SH, Loth F, et al. MR-intracranial pressure (ICP): a method to measure intracranial elastance and pressure noninvasively by means of MR imaging: baboon and human study. Radiology 2000;217:877-85 CrossRef Medline 